\title{
Wavelength control across the near IR spectrum with GalnNAs
}

\author{
R. S. Williams, W. M. McGee, M. J. Ashwin, and T. S. Jones ${ }^{a)}$ \\ Department of Chemistry, Imperial College London, London SW7 2AZ, United Kingdom \\ E. Clarke, P. Stavrinou, and J. Zhang \\ Department of Physics, Imperial College London, London SW7 2AZ, United Kingdom \\ S. Tomić \\ Computational Science and Engineering Department, CCLRC Daresbury Laboratory, Warrington, \\ Cheshire WA4 4AD, United Kingdom \\ C. P. A. Mulcahy \\ Cascade Scientific Ltd., ETC Building, Brunel Science Park, Uxbridge, Middlesex UB8 3PH, \\ United Kingdom
}

(Received 23 August 2006; accepted 11 December 2006; published online 18 January 2007)

\begin{abstract}
Accurate control of the photoluminescence (PL) emission wavelength over the range of $1.00-1.55 \mu \mathrm{m}$ has been achieved using GaIn(N)As multiple quantum well (MQW) structures, grown by plasma-assisted molecular beam epitaxy. By limiting the In content to $30 \%$, hence limiting the overall strain, wavelength-specific MQWs can be grown through simple control over the $\mathrm{N}$ content $(0 \%-5 \%)$. High crystalline quality and compositional control are demonstrated using high-resolution x-ray diffraction, secondary-ion mass spectroscopy, PL, and subsequent comparison to theoretical calculations using a ten-band $\mathbf{k} \cdot \mathbf{p}$ band-anticrossing model. The results reveal adherence to Vegard's law over a larger compositional range for GaInNAs than GaNAs. (C) 2007 American Institute of Physics. [DOI: 10.1063/1.2431756]
\end{abstract}

Dilute nitride semiconductor materials have received significant recent interest due to their potential applications in optoelectronics, especially for telecommunication devices operating in the near infrared spectrum. ${ }^{1}$ The quaternary alloy GaInNAs shows promise for the production of lasers with good device characteristics emitting with a wavelength of $\sim 1.3 \mu \mathrm{m} .^{2}$ Attempts to produce longer wavelength devices have proved less fruitful, with significant deterioration observed in material quality as the $\mathrm{N}$ content of the layers is increased. ${ }^{3}$ Research has focused on layers with relatively high In content $(35 \%-45 \%)$ and relatively low $\mathrm{N}$ content $(<3 \%)^{4,5}$ Of the few groups that have yet attempted to grow material with $5 \% \mathrm{~N}$ content, the majority of these have done so for single (or double) quantum well structures. ${ }^{5-7}$

In this letter we present the results of an investigation of $\mathrm{Ga}_{0.70} \mathrm{In}_{0.30} \mathrm{~N}_{x} \mathrm{As}_{1-x}$ multiple quantum wells (MQWs) grown by plasma-assisted molecular beam epitaxy (MBE) on $\operatorname{GaAs}(001)$, with $0 \leqslant x \leqslant 0.05$. The results demonstrate that longer wavelength emission (up to $1.55 \mu \mathrm{m}$ ) can be achieved using a lower In content than previously reported. The relatively low In content reduces the overall strain, enabling growth of high quality samples containing up to five QWs. Fine control over the $\mathrm{N}$ content and comparison to calculations performed using a ten-band $\mathbf{k} \cdot \mathbf{p}$ band-anticrossing (BAC) model $^{8}$ allow selectivity of the emission wavelength in the $1.00-1.55 \mu \mathrm{m}$ range.

Samples were grown in a solid-source MBE (DCA Instruments)-STM (Omicron Gmbh) system. Reflection high-energy electron diffraction (RHEED) was used to calibrate the incident source fluxes and monitor sample morphology during growth. Semi-insulating epi-ready GaAs(001) substrates were prepared by thermal desorption

\footnotetext{
a) Author to whom correspondence should be addressed; electronic mail: t.jones@imperial.ac.uk
}

of the oxide at $620{ }^{\circ} \mathrm{C}$. A $500 \mathrm{~nm}$ undoped GaAs buffer layer was deposited at $590{ }^{\circ} \mathrm{C}$ at a GaAs growth rate of $0.70 \mathrm{ML} \mathrm{s}^{-1}$ and an $\mathrm{As}_{4}$ overpressure (at a V:III flux ratio of $>4: 1)$. For the growth of the GaInNAs layers, active $\mathrm{N}$ species were provided by an EPI UNI-Bulb rf plasma source. The active $\mathrm{N}$ flux was monitored using a silicon photodiode detector system, which quantifies the total optical output of the plasma $\left(V_{\text {opt }}\right)$. After deposition of a $500 \mathrm{~nm}$ undoped GaAs buffer layer, the samples were cooled to $\sim 300{ }^{\circ} \mathrm{C}$ under an $\mathrm{As}_{4}$ flux, forming a thin As cap layer. The $\mathrm{N}$ source and the manipulator shutters further protected the substrate during plasma ignition and stabilization, minimizing surface damage caused by this process. ${ }^{9,10}$ A $50 \mathrm{~nm}$ GaAs buffer was then deposited at $400{ }^{\circ} \mathrm{C}$ to bury the nitrided surface and any possible surface imperfections resulting from plasma ignition. The MQW structures, all deposited at $400{ }^{\circ} \mathrm{C}$, consisted of either three or five, 7-8 nm thick GaIn(N)As QWs separated by 25 or $50 \mathrm{~nm}$ thick GaAs spacer layers (as the $\mathrm{N}$ source shutter is not $100 \%$ effective, some $\mathrm{N}$ enters the spacer layers). The $\mathrm{GaIn}(\mathrm{N})$ As layers were deposited at $1.00 \mathrm{ML} \mathrm{s}^{-1}$. The plasma was swiftly extinguished after growth of the last QW and a $250 \mathrm{~nm}$ undoped GaAs cap layer then grown at $590{ }^{\circ} \mathrm{C}$. The $\mathrm{N}$ composition in the layers was determined by ex situ high-resolution x-ray diffraction (HR-XRD) (004) rocking curves, secondary-ion-mass spectroscopy (SIMS), and photoluminescence (PL) measurements. The HR-XRD data were analyzed using Philips $X^{\prime}$ Pert Epitaxy 2.0, with the assumption that the In content in each QW was the same as that in the InGaAs calibration samples grown without N. The SIMS studies were referenced to separately grown dilute nitride bulk layer calibration samples. ${ }^{9}$ Uncapped samples grown for scanning tunneling microscopy (STM) were quickly removed to the STM chamber for filled-state imaging $(4-5 \mathrm{~V}, 0.3-0.5 \mathrm{nA})$ at room temperature, the quenching process effectively freezing 


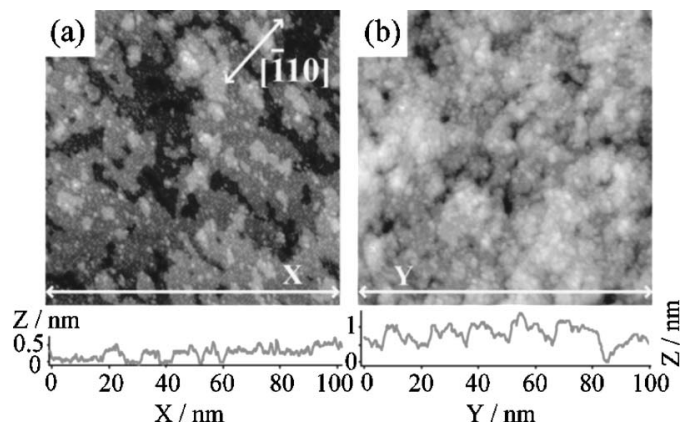

FIG. 1. $100 \times 100 \mathrm{~nm}^{2}$ filled-state STM images of $8 \mathrm{~nm}$ thick (a) $\mathrm{Ga}_{0.70} \mathrm{In}_{0.30} \mathrm{As}$ and (b) $\mathrm{Ga}_{0.70} \mathrm{In}_{0.30} \mathrm{~N}_{0.05} \mathrm{As}_{0.95}$ with corresponding topographic cross sections $X$ and $Y$.

the surface morphology. Streaky, rodlike, RHEED patterns were observed for all samples during deposition, suggesting planar, two-dimensional (2D) growth. ${ }^{10-12}$

The plan view STM images in Fig. 1 represent the surfaces of $8 \mathrm{~nm}$ thick $\mathrm{Ga}_{0.70} \mathrm{In}_{0.30} \mathrm{As}$ and $\mathrm{Ga}_{0.70} \mathrm{In}_{0.30} \mathrm{~N}_{0.05} \mathrm{As}_{0.95}$ layers grown on $\operatorname{GaAs}(001)$ and have root-mean-square (rms) roughnesses of 0.17 and $0.22 \mathrm{~nm}$, respectively. The slight increase in rms roughness for the $\mathrm{N}$ containing layer alludes to the existence of slight compositional inhomogeneities. There are clear differences in the terrace structure of the two surfaces. The InGaAs surface is characterized by large flat terraces, whereas GaInNAs has a much rougher texture, suggesting a significantly smaller diffusion length for both the In and Ga adatoms. ${ }^{12} \mathrm{Ga}_{0.7} \mathrm{In}_{0.3} \mathrm{~N}_{0.05} \mathrm{As}_{0.95}$ layers grown at the elevated temperature of $450{ }^{\circ} \mathrm{C}$ have much higher rms roughness of up to $1.2 \mathrm{~nm}$ and have been shown to exhibit a distinct three-dimensional undulating morphology, with pits up to $6 \mathrm{~nm}$ deep. This is attributed to spinodal decomposition within the growing layer. ${ }^{12}$ By comparison, the lowergrowth-temperature GaInNAs layers reported here adopt a much flatter 2D morphology, suggesting minimal compositional inhomogeneity.

Figure 2 compares the HR-XRD (004) rocking curves and low-temperature PL spectra of ternary $\mathrm{Ga}_{0.70} \mathrm{In}_{0.30} \mathrm{As}$ and quaternary $\mathrm{Ga}_{0.70} \mathrm{In}_{0.30} \mathrm{~N}_{0.05} \mathrm{As}_{0.95} \mathrm{MQW}$ structures grown under the same nominal conditions. The high crystalline quality of the $\mathrm{N}$ containing material is demonstrated by the clean, sharp features of the (004) rocking curve. The excellent match with the simulated curve suggests that the material is of high uniformity and confirms the 5\% N content. The PL spectra show emission peaks at 1.00 and $1.55 \mu \mathrm{m}$ for the $\mathrm{Ga}_{0.70} \mathrm{In}_{0.30} \mathrm{As}$ and $\mathrm{Ga}_{0.70} \mathrm{In}_{0.30} \mathrm{~N}_{0.05} \mathrm{As}_{0.95}$ samples, respectively, the broader peak for the dilute nitride sample being due to the existence of slight inhomogeneities within the layers. ${ }^{7}$ This is consistent with the small degree of roughening seen in the STM images in Fig. 1.

The relationship between $\mathrm{N}$ content, as measured by XRD, and PL emission wavelength is demonstrated in Fig. 3. A linear relationship is obtained over the entire range concerned. The lower inset shows the linear relationship between $\left[V_{\text {opt }}\right.$ /growth rate $]$ and the amount of $\mathrm{N}$ incorporated into the layers (up to 5\%); this illustrates the unity sticking coefficient for the active $\mathrm{N}$ species and the inverse dependence on growth rate of $\mathrm{N}$ incorporation. The experimental relationship between the $\mathrm{N}$ content and emission wavelength correlates exceptionally well with the theoretical values obtained from ten-band $\mathbf{k} \cdot \mathbf{p}$ BAC calculations, represented in the upper inset, where the $\mathrm{N}$-induced resonant band is inDownloaded 20 Jan 2007 to 148.79 .162 .143 . Redistribution subject
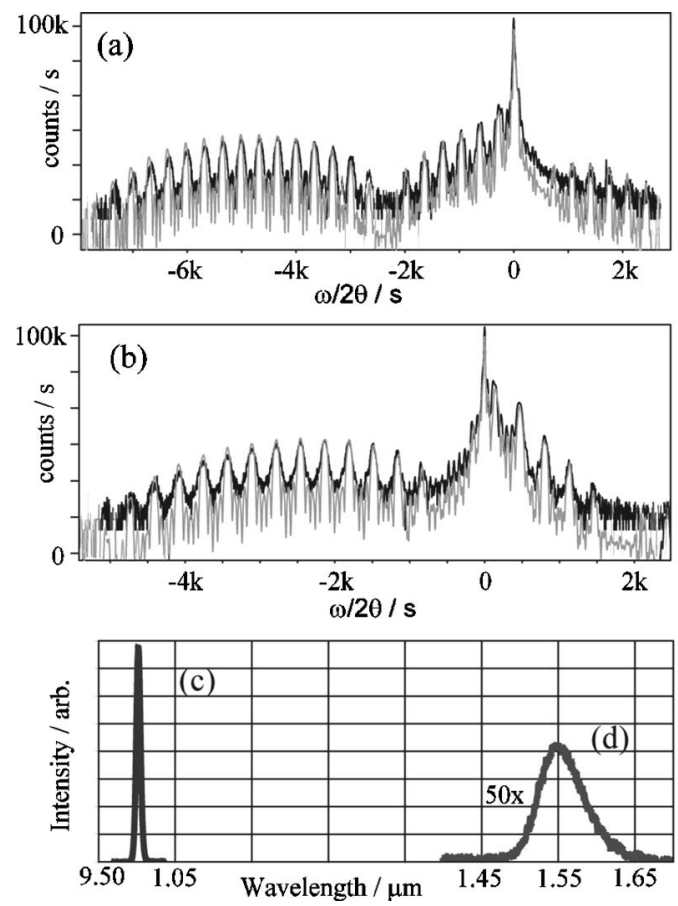

FIG. 2. HR-XRD rocking curves around the (004) reflection for (a) $\mathrm{Ga}_{0.70} \mathrm{In}_{0.30} \mathrm{As}$ and (b) $\mathrm{Ga}_{0.70} \mathrm{In}_{0.30} \mathrm{~N}_{0.05} \mathrm{As}_{0.95}$ : the black line shows the measured rocking curve, while the gray line shows the computer simulation. $15 \mathrm{~K}$ PL emission spectra for (c) $\mathrm{Ga}_{0.70} \mathrm{In}_{0.30} \mathrm{As}$ and (d) $\mathrm{Ga}_{0.70} \mathrm{In}_{0.30} \mathrm{~N}_{0.05} \mathrm{As}_{0.95}$.

cluded explicitly in the model. ${ }^{8}$ The favorable comparison between the experimental and theoretical results further suggests that the material is highly uniform with minimal compositional inhomogeneity. The data demonstrate that the complete range of wavelengths from 1.00 to greater than $1.55 \mu \mathrm{m}$, can be accessed with a straightforward alteration of the $\mathrm{N}$ content in the QW layers, with a fixed and relatively low In content.

Figure 4 shows the SIMS depth profiles for two MQW samples, with five periods of $8 \mathrm{~nm}$ thick $\mathrm{Ga}_{0.7} \mathrm{In}_{0.3} \mathrm{~N}_{0.05} \mathrm{As}_{0.95}$ (composition obtained from XRD) QWs separated by $50 \mathrm{~nm}$ thick nominally $\mathrm{GaAs}$ spacer layers. Incorporation of $\mathrm{N}$ only

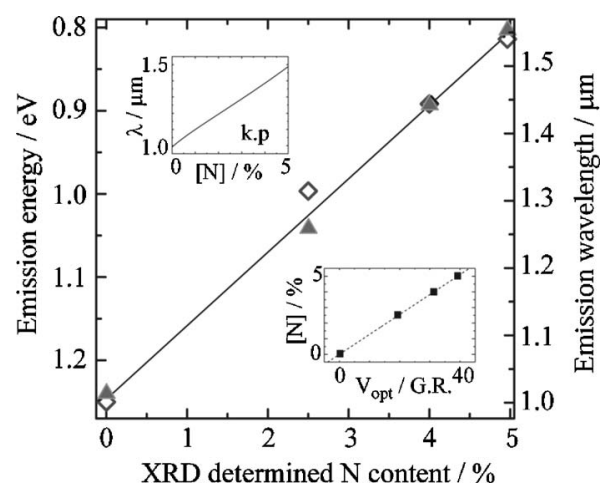

FIG. 3. Plot of XRD determined N content against 15 K PL emission wavelength and energy (represented by triangles). The diamonds represent the ten-band BAC k $\cdot \mathbf{p}$ theory predicted emission for the samples. Error bars have been omitted for clarity but the error in the XRD measured $\mathrm{N}$ content is $\pm 0.05 \%$, and emission linewidths are represented in Figs. 2(c) and 2(d). The lower right inset illustrates fine control over $\mathrm{N}$ content by variation of $V_{\text {opt }} /$ total growth rate. The upper left inset shows the ten-band BAC $\mathbf{k} \cdot \mathbf{p}$ theory derived variation of emission wavelength with $\mathrm{N}$ content, for $7 \mathrm{~nm}$ thick $\mathrm{Ga}_{0.70} \mathrm{In}_{0.30} \mathrm{~N}_{x} \mathrm{As}_{1-x}$ QWs separated by $50 \mathrm{~nm}$ thick GaAs spacer layers at $15 \mathrm{~K}$. All data sets have linear fits with $R^{2}>0.99$.

to AIP license or copyright, see http://apl.aip.org/apl/copyright.jsp 


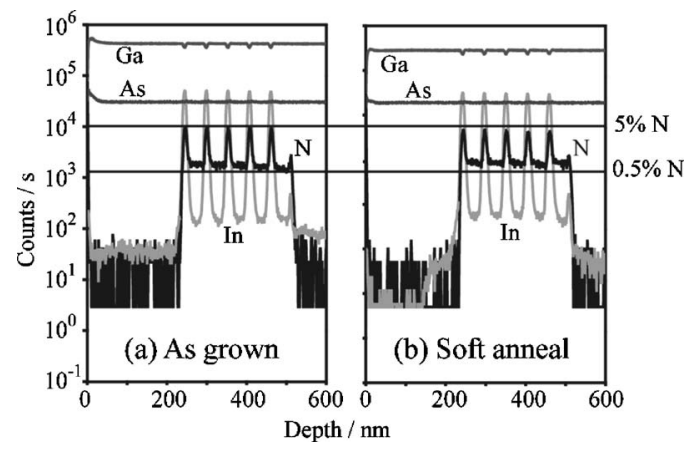

FIG. 4. Typical SIMS depth profiles of two $\mathrm{Ga}_{0.70} \mathrm{In}_{0.30} \mathrm{~N}_{0.05} \mathrm{As}_{0.95}$ layers: (a) as grown and (b) in situ postgrowth annealed. Lines signifying $0.5 \%$ and 5\% $\mathrm{N}$ content are included.

occurs when the rf plasma is present $;{ }^{9}$ immediate cessation of $\mathrm{N}$ incorporation when the plasma is extinguished directly after growth of the final QW is clear in the depth profile as is the $\mathrm{N}$ content in the spacer layers. Initiation of the plasma source produces a less significant $\mathrm{N}$ peak, located to the right of the QWs in the depth profiles.

The slight variation in $\mathrm{N}$ composition from Fig. 4(a) to Fig. 4(b) is the result of an in situ, postgrowth soft anneal, the latter being held at $620^{\circ} \mathrm{C}$ for 30 min under an As overpressure. The XRD measured N content and the PL emission wavelength were unchanged by the annealing process; however, the PL emission intensity was quadrupled. As there was no discernable difference in XRD and emission wavelength, it is reasonable to suggest that the soft anneal did not cause any reorganization of species at lattice sites. ${ }^{5}$ The slight reduction in QW N content and slight increase in spacer layer $\mathrm{N}$ content must presumably be caused by movements of interstitial $\mathrm{N}$, which readily diffuses from regions of high concentration (the QWs and the plasma ignition peak) to regions of low concentration (the spacer layers) during the anneal. Redistribution of the interstitial $\mathrm{N}$ throughout the MQW structure could explain the increase in PL emission intensity as the number of nonradiative defects, associated with interstitial $\mathrm{N}$, in the QWs is reduced and material quality is improved. ${ }^{13}$

Limited depth resolution in SIMS leads to an apparent increase in the measured QW widths; this can be inferred if the depth profile peaks are sharply pointed rather than flattopped, which is the case for the profiles in Fig. 4. Consequently, SIMS measured $\mathrm{N}$ concentrations are likely to be slightly lower than is actually the case. Nevertheless, close agreement of the XRD and SIMS measured $\mathrm{N}$ content reveals that almost all $\mathrm{N}$ in the QWs occupies lattice sites. The low miscibility of $\mathrm{N}$ in GaAs makes it difficult to incorporate more than 3\% N into GaNAs QWs, without a substantial deterioration in structural quality. ${ }^{14}$ The limited solubility leads to a breakdown of Vegard's law for higher $\mathrm{N}$ concentrations as $\mathrm{N}$ atoms take up interstitial occupancy within the lattice. Our results show that this is not the case for GaIn$\mathrm{NAs}$, with $\mathrm{N}$ incorporation as high as $5 \%$ possible, with only a very small proportion of $\mathrm{N}$ occupying interstitial sites. As In has a larger atomic radius than $\mathrm{Ga}$, the overall lattice perturbation around a small $\mathrm{N}$ atom is reduced by presence of In, resulting in reduced overall strain and allowing a greater proportion of $\mathrm{N}$ atoms to occupy lattice sites.

In summary, we have demonstrated that the alteration of the $\mathrm{N}$ incorporation for a fixed group III flux leads to an easily accessible wide range of emission wavelengths. We have shown that it is possible to introduce significantly higher levels of $\mathrm{N}$ (up to 5\%) into the MBE layers in an MQW system than previously accomplished, without significant decrease in material quality and uniformity. Good agreement between the $\mathrm{N}$ content measured using a variety of techniques, and additionally from a theoretical standpoint with a ten-band $\mathbf{k} \cdot \mathbf{p}$ BAC modeling approach, illustrates that the material is of high quality and alludes to a closer adherence to Vegard's law for GaInNAs than for GaNAs.

The authors are grateful to the Ultrafast Photonics Consortium (UPC) and the Engineering and Physical Sciences Research Council (EPSRC) U.K. for the studentship for one of the authors (W.M.M.) and the CCP3 Consortium for supporting this work.

${ }^{1}$ J. S. Harris, Jr., Semicond. Sci. Technol. 17, 880 (2002); M. Kondow, K. Uomi, A. Niwa, T. Kitatani, S. Wakahiki, and Y. Yazawa, Jpn. J. Appl. Phys., Part 1 35, 1273 (1996).

${ }^{2}$ A. Y. Egorov, D. Bernklau, D. Livshits, V. Ustinov, Z. I. Alferov, and H. Riechert, Electron. Lett. 35, 1643 (1999); Y. Q. Wei, Y. Fu, X. D. Wang, P. Modh, P. O. Hedekvist, Q. F. Gu, M. Wang, and A. Larsson, Appl. Phys. Lett. 87, 081102 (2005); R. Fehse, S. Tomic, A. R. Adams, S. J. Sweeney, E. P. O'Reilly, A. Andreev, and H. Riechert, IEEE J. Sel. Top. Quantum Electron. 8, 801 (2002).

${ }^{3}$ J. M. Ulloa, A. Hierro, M. Montes, B. Damilano, M. Hugues, J. Barjon, J.-Y. Duboz, and J. Massies, Appl. Phys. Lett. 87, 251109 (2005); P. R. Chalker, T. J. Bullough, M. Gass, S. Thomas, and T. B. Joyce, J. Phys.: Condens. Matter 16, S3161 (2004); J. Y. Duboz, J. A. Gupta, Z. R. Wasilewski, J. Ramsey, R. L. Williams, G. C. Aers, B. J. Riel, and G. I. Sproule, Phys. Rev. B 66, 085313 (2002).

${ }^{4}$ E. Tournie, M. A. Pinault, S. Vezian, J. Massies, and O. Toottereau, Appl. Phys. Lett. 77, 2189 (2000); J. M. Chauveau, A. Trampert, M. A. Pinault, E. Tournie, K. Du, and K. H. Ploog, J. Cryst. Growth 251, 383 (2003); L. Geelhaar, M. Galluppi, G. Jaschke, R. Averbeck, H. Riechert, T. Remmele, M. Albrecht, M. Dworzak, R. Hildebrant, and A. Hoffmann, Appl. Phys. Lett. 88, 011903 (2006); B. Damilano, J. Barjon, J. Y. Duboz, J. Massies, A. Hierro, J. M. Ulloa, and E. Calleja, ibid. 86, 071105 (2005). ${ }^{5}$ G. Jaschke, R. Averbeck, L. Geelhaar, and H. Riechert, J. Cryst. Growth 278, 224 (2005).

${ }^{6}$ M. Fischer, D. Gollub, M. Reinhardt, M. Kamp, and A. Forchel, J. Cryst. Growth 251, 353 (2003).

${ }^{7}$ J. Misiewicz, P. Sitarek, K. Ryczko, R. Kudrawiec, M. Fischer, M. Reinhardt, and A. Forchel, Microelectron. J. 34, 737 (2003).

${ }^{8}$ S. Tomic, E. P. O'Reilly, R. Fehse, S. J. Sweeney, A. R. Adams, A. D. Andreev, S. A. Choulis, T. J. C. Hosea, and H. Riechert, IEEE J. Sel. Top. Quantum Electron. 9, 1228 (2003).

${ }^{9}$ C. P. A. Mulcahy, S. J. Barker, R. S. Williams, M. Hopkinson, M. J. Ashwin, P. N. Stavrinou, G. Parry, S. Biswass, and T. S. Jones, Appl. Surf. Sci. 252, 7218 (2006).

${ }^{10}$ W. M. McGee, P. A. Bone, R. S. Williams, and T. S. Jones, Appl. Phys. Lett. 87, 181905 (2005).

${ }^{11}$ J. H. Neave and B. A. Joyce, J. Cryst. Growth 44, 387 (1978); H. J. Parry, M. J. Ashwin, J. H. Neave, and T. S. Jones, Semicond. Sci. Technol. 17, 1209 (2002).

${ }^{12}$ W. M. McGee, R. S. Williams, M. J. Ashwin, and T. S. Jones, Surf. Sci. 600, L194 (2006).

${ }^{13}$ M. Kondow and T. Kitatani, Semicond. Sci. Technol. 17, 746 (2002); A. Hierro, J. M. Ulloa, J. M. Chauveau, A. Trampert, M. A. Pinault, E. Tournée, A. Guzman, J. L. Sanchez-Rojas, and E. Calleja, J. Appl. Phys. 94, 2319 (2003).

${ }^{14}$ A. R. Denton and N. W. Ashcroft, Phys. Rev. A 43, 3161 (1991). 